accounts' had decided that scientific microhistories were 'over', and he was thus finding it increasingly difficult to take anything on at all in this genre. This is despite a lack of real evidence that the public's appetite for books such as Simon Singh's Fermat's Last Theorem or Mark Kurlansky's Cod is satiated.

The upside to all this is that there has been a move back towards traditional history - epics such as Deborah Cadbury's The Dinosaur Hunters or Jenny Uglow's The Lunar Men. This trend is hardly surprising. In an increasingly weighty world, there is an increasing demand for weighty books, including agenda-driven titles such as Eric Schlosser's Fast Food Nation, Bjørn Lomborg's The Skeptical Environmentalist, and even aspirational titles, such as Roger Penrose's The Road to Reality, which offers nothing less than a complete advanced course in modern physics.

The market for popular science is still there - but as an echo of the original big bang. Publishers are increasingly sophisticated and discerning, and there has been a shakedown in the number of commercial houses who know, like and succeed with science. Ironically for an agent, I happen to think this is good news. It means that authors are taken on only by genuinely committed editors, and this in turn means that when their books do appear, people are more likely to buy, read and talk about them more a case of Hawking radiation than the Hawking phenomenon.

Peter Tallack was formerly the book-review editor of Nature and science publishing director of Weidenfeld \& Nicolson. He is now a partner of the literary agency Conville \& Walsh, 2 Ganton Street, London W1F 7QL, UK.

\section{The search for meaning}

\section{The Dynamic Dance: Nonvocal Communication in African Great Apes}

by Barbara J. King

Harvard University Press: 2004. 240 pp.

$\$ 29.95, £ 19.95$, €27.70

\section{W. Tecumseh Fitch}

The idea that certain primate vocalizations are information-bearing signals is an old one. In 1892, R. L. Garner used playbacks of monkey vocalizations to deduce that some monkey calls had referential significance they were what we now know as food or alarm calls. But it was much later, only about fifty years ago, that the concepts of 'information' and 'signal' became clear enough to be formalized mathematically by Norbert Wiener and Claude Shannon, giving birth to modern information theory.

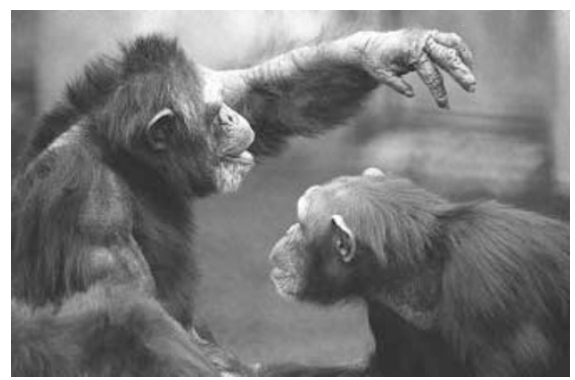

years observing captive chimpanzees, bonobos and gorillas. The first 85 pages of this book argue that the 'signaller-receiver' model of animal communication (King calls it the Shannon/Marler framework, acknowledging the influence of ethologist Peter Marler) must be supplanted by King's new approach, dynamic systems theory. Dynamicsystems theorists eschew quantitative data, reject the notion that animal signals contain information, and focus instead on interactive aspects of ape social behaviour (their "dynamic dance").

The core insight in King's book is that communicative exchanges among apes are 'co-regulated': interactions unfold contingently and unpredictably. King is certainly correct that ape communication systems (like those of many other animals) are complex and contingent. Far from being simple robotic automata that respond to a particular signal in a fixed and pre-programmed fashion, apes show considerable social intelligence, interpreting each other's actions against a backdrop of their history and current social context, and responding appropriately. But this is also true of two dogs interacting, as is quickly apparent to even casual observers.

Recognition of contingency and context in communication provides a rationale not for rejecting information theory, but for extending it, as its founders recognized. Information theory rigorously specifies a quantitative upper bound to the information borne in signals versus that supplied by receivers - surely a useful tool for understanding how receivers interpret and respond to communicative behaviour. I have rarely seen the baby-bathwater distinction so consistently elided as in this book.

The second part of the book features detailed descriptions of ape behavioural interactions, many based on King's own observations. King studiously avoids any interpretations of ape intentionality. Furthermore, because she rejects quantitative data (which she believes obscure the underlying co-regulatory nature of communication), we are given no summaries or statistics. Unfortunately, these two theoretical convictions conspire to make this section rather heavy going.

Space precludes quoting these descriptions in full, but here is a short excerpt of four from a sequence of nineteen behaviours: "Elikya watches Tamuli eat, then pulls on Tamuli's hand... As Tamuli chews, Elikya attempts to take a bit of orange but Tamuli turns her head away. Elikya again tries to take a bit of Tamuli's chewed orange but Tamuli pulls her head back; Elikya climbs off Tamuli and goes back to her mother." The middle 100 pages of the book are full of such "qualitative data". Although King is undoubtedly a sensitive observer of ape interactions, she rarely shares her 
interpretations of these sequences with the reader, and these descriptions are presented primarily as demonstrations of the co-regulated nature of ape interactions. Although the cover describes the book as "eye opening", I personally found these long and detailed descriptions of ape interactions made excellent bedtime reading.

In conclusion, like most clarion calls to scientific revolution, this book both oversimplifies the opposing viewpoint and overstates the significance and novelty of its own stance. King is correct that information theory should be extended to incorporate context and meaning, but this point was noted by the theory's founders and is widely recognized today. The reader seeking an alternative in 'dynamic systems theory', as presented in this book, will find little more than a promissory note, and would probably be better served by spending a day at the zoo watching ape social behaviour themselves.

W. Tecumseh Fitch is at the School of Psychology, University of St Andrews, St Andrews,

Fife KY16 9JU, UK.

\section{Back to the roots}

\section{Ethnoflora of the Soqotra}

Archipelago

by Anthony G. Miller \& Miranda Morris Royal Botanic Garden Edinburgh: 2004. 759 pp. $£ 75$

\section{Jan Salick}

Stunning and sumptuous in design, Ethnoflora of the Soqotra Archipelago sets a contemporary standard for describing the plant life of an area and its uses. And what better focus than the exotic, unique and rich flora of the Soqotra Archipelago, south of the Arabian peninsula, off the eastern horn of Africa? An ethnoflora, although described in the book simply as the product of botanists working closely in the field with ethnographers and linguists, surpasses this process by matching diverse disciplines, objectives and issues. It combines traditional and scientific knowledge; botanical and ethnographic-linguistic description; conservation and sustainable management; and geography, plants and people.

Of the people, and for the people, of Soqotra, this work is accomplished here by an eminently qualified team from the Royal Botanic Garden Edinburgh. Anthony G. Miller is the foremost botanist of the Arabian peninsula; Miranda Morris is a linguist and ethnographer of the southern Arabian peninsula; Diccon Alexander is an illustrator, designer and photographer; and Ruth Atkinson is an ecologist, taxonomist and editor of this volume.

This ethnoflora differs from traditional

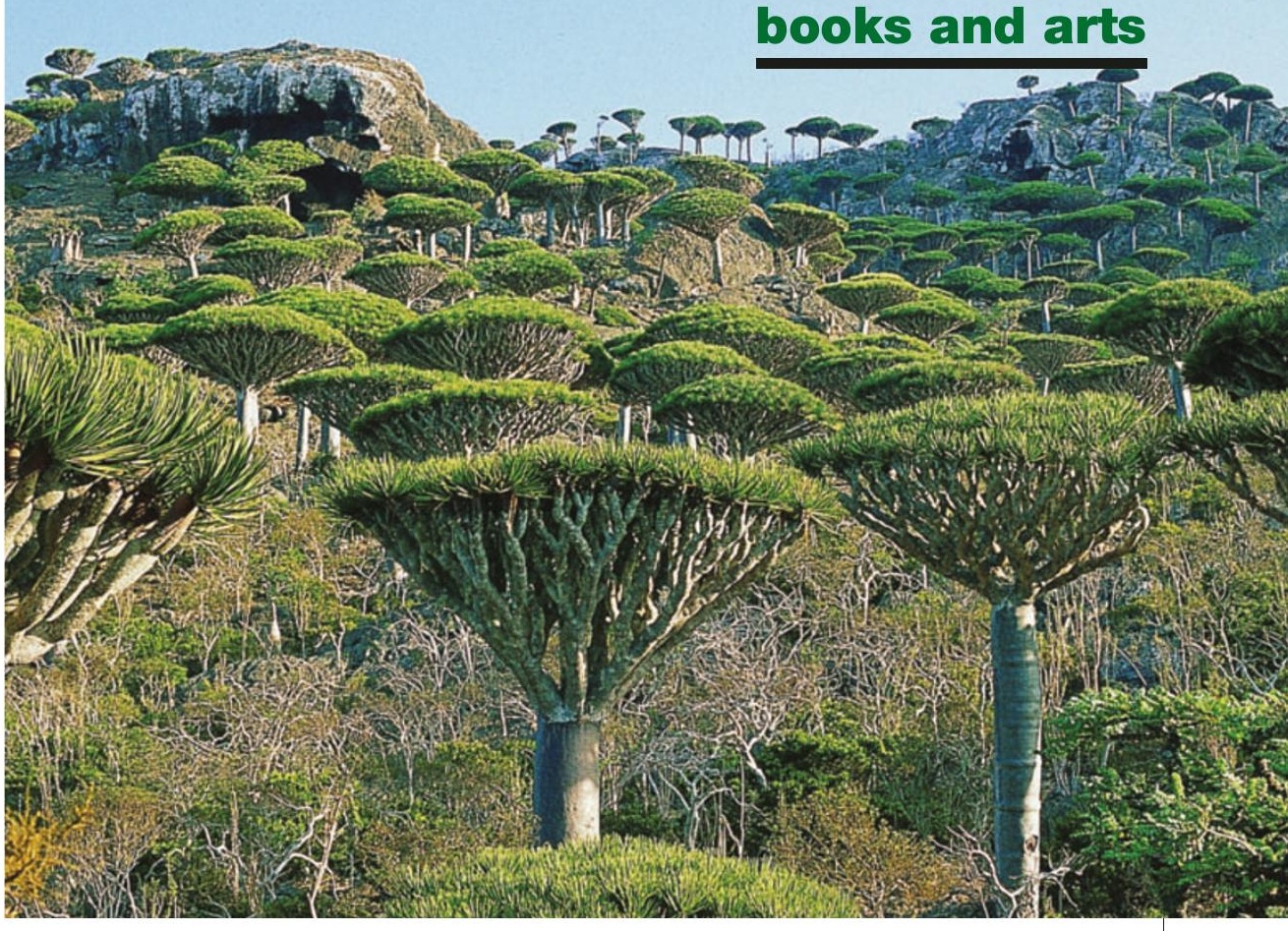

Local knowledge: 'dragon's blood', the resin from Dracaena cinnabari trees, is used to fight infections.

floras in several ways. Comprehensive ethnographic information is presented for all species used by the islanders and their livestock. The fully illustrated key, figures and photographs illustrate all of the species and many of their characters - even the most basic, such as leaf position. Conventional taxonomic descriptions are brief and include minimal botanical terminology. These characteristics make the book meaningful and useful to a wider audience than professional botanists, including local people (if they can read English). For the benefit of conservationists and sustainable developers, all of the endemic species in the book are rated using the World Conservation Union's threat categories.

Soqotra is home to an ancient, useful flora and 50,000 traditional people who have sustainably managed their unique centre of biodiversity and their environment for millennia. So at a deeper level, this emphasis on traditional sustainable use and management is a theme that fundamentally distinguishes this work from other floras.

The Soqotran flora cannot be discussed without mentioning the astounding plants and the landscape in which they thrive. 'Dragon's blood' resin, for example, is collected from the plant Dracaena cinnabari and is used to fight infection and inflammation. Bitter aloes - the juice of Aloe perryihas many important pharmaceutical and medicinal uses. The latex of the Soqotran desert rose (Adenium obesum sokotranum) is often applied to wounds. And how weird is the cucumber tree, Dendrosicyos socotrana? On Soqotra, these bizarre plants exist in an almost surreal environment. The endemic flora of Soqotra - one-third of its entire flora - either split from Gondwana when the ancient southern supercontinent fragmented, or migrated to the islands from neighbouring continents and radiated to form a unique and fantastic flora.

This weighty book cannot be reviewed without extolling its stunning beauty. There is a plethora of coloured photographs, original line drawings, illustrated keys, maps, images and historic drawings. The pages are handsomely designed and never crowded. The text is easy on the eye (although the location maps are somewhat faint) and the book's organization is readily apparent and consistent.

It is difficult to find weaknesses with this exceptional book. However, my taxonomic colleagues are always up to the challenge: they have pointed out some problems with the one big key they tried (group G) and question the accuracy of some sketches in the keys. They also challenge some of the details about certain families: for example, recent molecular studies show that Sisymbrium includes 45 species, not 90 . Of more concern to me, as an ethnobotanist attempting to turn a historically descriptive field into a modern science, is the predominance of description and lack of analysis in the book.

In a US National Science Foundation workshop, "Intellectual Imperatives in Ethnobiology", held in the Missouri Botanical Garden in 2002, we emphasized the need "to explore modern methodology appropriate for studying people-biota-environment interactions; to quantitatively analyze our multidisciplinary data based on hypotheses; [and] to develop interdisciplinary education programs to train students and practitioners of ethnobiology." In Ethnoflora of the Soqotra Peninsular there is little evidence of modern methods, analyses or even education extended to Soqotrans. Additionally, many ethical issues - intellectual-property rights, 